THURSDAY, OCTOBER 28, 1875

\section{SIXTH REPORT OF THE SCIENCE COMMISSTON}

TH

H REE times within the last twelve years a Royal

Commission has reported on the science teaching of our higher schools. In I864 the Public Schools Commission announced that from the largest and most famous schools of all it was practically excluded. In 1868 the Endowed Schools Commission declared that the majority of school teachers had accepted it as part of their school work. The Science Commissioners of 1875 , in their Sixth Report, on Science Teaching in Schools, testing this statement by inquiry, reports that of 128 endowed schools examined by them not one-half has even attempted to introduce it, while of these only 13 possess a laboratory, and only ro give to the subject as much as four hours a week. And this statement is curiously illustrated by the statistics of the recent Oxford and Cambridge School Examination, which show that out of $46 \mathrm{I}$ candidates for certificates from 40 first-class schools, while 438 boys took up Latin, 433 Greek, 455 Elementary Mathematics, 305 History; only 2 I took up Mechanics, 28 Chemistry, 6 Botany, 15 Physical Geography.

In a volume whose research and condensation make it not only a monument of conscientious toil, but an invaluable handbook to all who are labouring to work out practically the great problem of which it treats, the Commissioners investigate the obstacles which have caused the endowed schools to defy the weighty recommendations of former Commissions, the unanimous verdict of educational authorities outside the scholastic profession, and the increasingly urgent demands of English public opinion. They find the schoolmasters' excuses to be threefold ; absence of funds, want of time, and scepticism as to the educational value of science in comparison with other subjects. A large portion of the Appendix is devoted to the consideration of these difficulties; to sifting the allegations on which they rest, and to balancing against them the experience of those teachers who have faced and successfully met them. Showing in detail the comparatively trifling cost at which indispensable apparatus can be obtained, the Commissioners nevertheless admit the rarity, in the present state of English culture, either of independent science teachers suited to the larger schools, or of men, such as poorer schools desiderate, combining literary with scientific knowledge. This, however, is an evil of the past rather than of the future, since not the least amongst the advantages expected from a reformed system of school teaching is the creation of a race of able teachers, general as well as special. The relative value of science as an implement of mental training is next discussed. Its peculiar excellence is briefly vindicated, as cultivating in a way attainable by no other means the habits of observation and experiment, of classification, arrangement, method, judgment ; and its suitability to the capacities of the very youngest boys is testified to by Faraday, Hooker, Rolleston, Carpenter, and Sir W. Thomson. Lastly, it is shown that, if this be so, the argument from want of time is no argument at all; that the hours are already wasted which condemn the half of a boy's faculties to stagnation and render education one-sided and incomplete; and that the claims of different branches of instruction may be easily adjusted by economy of time, improvement in methods, and excision of superfluous studies.

On a review of all these objections and of the answers offered to them, and taking into account the dicta of former Commissioners and the practice of other countries, the Report advises that literature, mathematics, and science should be the accepted subjects of education up to the time at which boys leave school, and should all three be made compulsory in any School Leaving-Examination or University Matriculation; but that after entering the University students should be left to choose for themselves amongst these lines of study, and need pass no subsequent examination in subjects other than the one which they select. As regards the teaching of science, they recommend that it should commence with the beginning of the school career; that not less than six hours a week should be devoted to it, and that in all school examinations as much as one-sixth of the marks should be allotted to it.

These recommendations possess the two great excellences of authoritativeness and clearness. They are supported by a host of experienced witnesses, as well as by the eminent names whose signatures follow them. Their ideal of school education is simplicity itself. The supremacy of Classics is to be dethroned; the artifices of stratification and bifurcation are to be discarded; literature, mathematics, and science are to share a boy's intellect between them from the very first, until a leavingexamination which shows his progress to have been satisfactory in all three sets him free to follow his inclination by pursuing exclusively the subject which suits him best; happy since eminence in that one will not have been purchased by entire ignorance of all the others. Unfortunately, though most necessarily-for this Report concerns schools only-the curtain drops upon this interesting moment of transition, shutting out of view the influence which University Scholarships and Exhibitions exercise upon school work, and thus ignoring an obstacle to the realisation of the programme far greater than want of money, want of time, or want of appreciation, in the schools themselves.

What is the avowed object and purpose of the higher English school education? Is it the even and progressive development of young minds? the strengthening in equal proportion of the faculties of imagination, memory, reason, observation? the opening doors of knowledge in the plastic time of youth, which if not opened then will be fast closed in later years by the pressure of active work, or habitual exclusiveness, or energies paralysed through disuse? Nothing of the kind. It is constructed entirely with the aim of winning certain prizes; for scholarships with which a costly University bribes men to come to it for education; for class-lists leading up to College Fellowships ; for the lucrative posts of military and civil service. In all these, but most of all where the Universities can determine the ordeal, one principle of success has been established, and that principle is one-sidedness. The candidate for India, for Woolwich, for Cooper's Hill, must at an early age select certain subjects and throw overboard all the rest. The childish aspirant to the entrance scholarships of a public school is placed in the hands 
of a crammer at eight years old, that at thirteen he may turn out Latin verses as a Buddhist prayer-mill turns out prayers, and may manifest, as a distinguished headmaster has lately said, to the eye of a teacher searching for intelligence, thoughtfulness, promise, intenseness, "a stupidity which is absolutely appalling." His scholarship won, he is pledged to pursue a course whose benefits are tangible and its evil consequences remote. The Universities have stamped upon all the schools one deep certainty, that for a boy to be "all round,". as it is called, is the irremissible sin; that a schoolmaster who teaches with reference to intellectual growth and width of culture sacrifices thereby all hope of the distinctions which make a school famous and increase its numbers. If a classical scholarship is desired, science and mathematics are abandoned : nay, the palm of literary excellence is conceded even to men ignorant of the noblest literature in the world, their own birthright and inheritance, and knowing less of the history and structure of the English language than a fourth form boy knows of Greek. If mathematical success is aimed at, literature and science are ignored; if the few science scholarships existing tempt candidates from any of "the thirteen schools which possess a laboratory," mathematics in part and literature altogether must be given up. It would be waste of words to point out the fatal tendency of this separative process ; to show how mere linguistic training needs the rationalising aid of scientific study, or how exclusive science hardens and materialises without the refining society of literature; yet such divorce is inevitably due not to the convictions of schoolmasters, not to the influence of parents, not to the prepossessions of the public, but to the irresistible force of the University system, which makes narrowness of intelligence and imperfect knowledge the only avenues to distinction or to profit.

It is true that an attempt to alter this involves little short of a revolution; but by all accounts a revolution is at hand. It is not for nothing that a parliamentary investigation into the expenditure of college endowments should have been supported by members of the colleges themselves, or that a proposal to distribute college scholarships and exhibitions by a central authority in accordance with the results of the leaving-examination should have emanated from eminent university teachers. For it cannot be too strongly urged that college scholarships stand on very different ground from university prizes or degrees. It is easy for Parliament to lay down rules which shall control the latter once for all; it is not easy to bind the actions of some forty different foundations, each electing its own scholars according to its own idiosyncrasies, or in obedience to the changing wills of bodies in a perpetual state of flux. It may still be audacious, but it is no longer novel, to suggest that, supposing future legislation to retain the college scholarships at all, they should be awarded by the authority of Government, in strict connection with leaving-examinations which Government shall conduct, and in reward not of special but of general proficiency. For this the scheme of the Commissioners virtually contends; into regions beyond this the Report before us necessarily does not enter.

It will be seen that we accept, and recommend all teachers to accept, the scheme of the Commissioners unreservedly as a working basis of educational improvement. It may not be ideally perfect ; it may invite opposition on points of detail ; but it is the resultant of all the intellectual forces which have hitherto been brought to bear upon the subject; and while agreeing with all its witnesses on the principle that wide general training should precede specialisation of study, it attains extreme simplicity of arrangement by allotting the first of these to the Schools and the last to the Universities. Do not let us forget that the cry which has arisen hitherto from all the head-masters on the point of scientific teaching has been a cry for Iguidance ; for commanding and intelligent leadership; for authoritative enlightenment as to the relative value and the judicious sequence of scientific subjects; for information as to text-books, apparatus, teachers. For the first time this cry is met by an oracle whose authority no one will question, and whose completeness of delivery all who study its utterances will appreciate. Schoolmasters anxious to teach science, and doubtful how to set about it, will meet all the facts which can enlighten them in the Appendices to the Report. They will find lists of accredited text-books, specimens of examination papers, varieties of school time-tables, priced catalogues of apparatus, syllabi of lectures and experiments, botanical schedules and tables, plans and descriptions of laboratories, workshops, museums, botanic gardens ; programmes and reports of school scientific and natural history societies. They will learn how costly a temple could be built to Science at Rugby, and how modestly it could be housed at Taunton. They will see how Mr. Foster teaches physics, how Mr. Hale teaches geography, how Mr. Wilson teaches Erdkunde. And they will accept all this as coming from men who have a right to speak, and who wield an experience such as has not been amassed before. On any legislative change which impends over the system and the endowments of the higher English education, the body of scientific opinion is strong enough, if united, to impress its own convictions; disunion alone can paralyse it. All who feel the discredit of past neglect, its injury to our national intellect, and its danger to our national prosperity, will do well to support by unqualified adhesion the first attempt that has been made to probe its causes, and the first consistent and well-considered scheme that has been put forth for its removal.

W. TUCKWELL

\section{DREW'S “ FUMMOO AND KASHMIR"}

The Fummoo and Kashmir Territories. A Geographical Account. By Frederick Drew, F.R.G.S., F.G.S., Associate of the Royal School of Mines, (London: Stanford, 1875.)

$7 \mathrm{HE}$ author of this work was for ten years, from 1862 , 1 in the service of the Maharaja of Kashmir, his primary duty apparently being the investigation of the mineral resources of the territory. During this period his duties led him to visit many parts of the Maharaja's dominions, and thus he had unusual opportunities of becoming well acquainted with the various districts and peoples under the sway of that ruler. Mr. Drew's previous training had qualified him to take intelligent advantage of his position and opportunities, and the result is the present bulky work, occupying 550 pages. 